\title{
Impacto en el presupuesto institucional de las atenciones de baja complejidad ${ }^{1}$
}

\section{Impact on the institutional budget of low-complexity medical care}

\author{
Marco Antonio Cuadros Talattino ${ }^{2}$ \\ Universidad Nacional Mayor de San Marcos \\ marcuadro@yahoo.com \\ https://orcid.org/0000-0002-4124-5536
}

Recibido: 03/06/2019

Aceptado: 25/11/2019

\section{RESUMEN}

El presente estudio analiza el impacto que, en el presupuesto ejecutado en consulta externa del Instituto Nacional de Oftalmología (INO), generan las atenciones realizadas a los pacientes con patologías de baja complejidad, los cuales debieron ser atendidos en los establecimientos de salud del primer nivel de atención, en el periodo 2010-2015. Se identifican las patologías, se cuantifican las consultas y se estima el presupuesto ejecutado en consulta externa y en patologías de baja complejidad. El estudio encuentra que, el impacto de las atenciones con patologías de baja complejidad representa el 23,54\% del presupuesto en consulta externa del INO, durante el período de estudio. Este nivel significa una reducción del 36\% en consultas de pacientes con patologías de alta complejidad. Asimismo, del total del presupuesto ejecutado en patologías de baja complejidad, el 65\% corresponde a consulta general (medicina oftalmológica) y 35\% a consulta de refracción (medición de la vista). Por otro lado, se encuentra que el presupuesto ejecutado en consulta externa durante el período, representa el $21 \%$ del presupuesto institucional ejecutado en el INO. El impacto estimado se considera importante, por lo que se recomienda su reducción y/o corrección.

Palabras Claves: consulta externa; primer nivel; atención; presupuesto.

JEL: I1

(C) Los autores. Este artículo es publicado por Pensamiento Crítico de la Facultad de Ciencias Económicas, Universidad Nacional Mayor de San Marcos. Este es un artículo de acceso abierto, distribuido bajo los términos de la licencia Creative Commons Atribucion - No Comercia_Compartir Igual 4.0 Internacional. (http:// creativecommons.org/licenses/by-nc-sa/4.0/) que permite el uso no comercial, distribución y reproducción en cualquier medio, siempre que la obra original sea debidamente citada. 


\section{ABSTRACT}

The present study analyses the impact on the National Ophthalmological Institute (INO)'s budget executed in outpatient services due to medical care for patients with low-complexity pathologies, who should be treated in the primary care centers, during the period 2010-2015. Pathologies were identified, medical consultations were quantified and the budget executed in outpatient services and low-complexity pathology was estimated. The study concludes that the impact of medical care on patients with low-complexity pathologies represents $23,54 \%$ of the INO's budget executed in outpatient services during the study period. This level represents a reduction of $36 \%$ in consultations for patients with high-complexity pathologies. Moreover, out of the total budget executed in low-complexity pathologies, $65 \%$ refers to general consultation (ophthalmological medicine) and 35\% to refraction test (visual acuity measurement). On the other hand, it is found that the budget executed in outpatient services during this period represents $21 \%$ of the INO's institutional budget. The estimated impact is considered important; therefore, its reduction and/ or correction are recommended.

Keywords: outpatient service; primary care; medical care; budget.

JEL: I1 


\section{Introducción}

Las afecciones oftalmológicas no son causa de mortalidad, pero pueden llevar a la invalidez visual. La ceguera tiene profundas y evidentes repercusiones socioeconómicas en toda la sociedad. Los pacientes ciegos, por lo general, manifiestan una baja productividad laboral, requieren de una rehabilitación y control permanente, así como de una educación especial. Todo ello, generan costos secundarios que son asumidos por la sociedad, la familia y, sobre todo, el afectado (Tirado, 2011),

Los efectos socio-económicos de la ceguera se manifiestan en una mayor dificultad de la comunidad afectada para enfrentarse a los nuevos desafíos del desarrollo social. Estas dificultades se expresan en una menor disposición cognitiva- motora para adquirir los conocimientos básicos de lecto-escritura y los aprendizajes de las actuales tecnologías de información y comunicación (TICs). De la misma manera, ven reducidas sus posibilidades de acceso a un trabajo decente y otras actividades de esparcimiento y realización personal (UNESCO, 2009).

Los servicios de salud que brinda el Estado se organizan en el sistema de salud pública, con la finalidad de atender los requerimientos de salud de la población. En este sistema, una de las instituciones públicas encargada de atender a los pacientes que sufren de deficiencias visuales, es el Instituto Nacional de Oftalmología (INO). Tiene como objetivos primordiales el desarrollo de la investigación y preparación docente, así como la atención especializada y altamente especializada en oftalmología, con la finalidad de disminuir las tasas de prevalencia de las enfermedades que causan discapacidad por ceguera evitable.

Por otro lado, el INO ha iniciado el desarrollo de la Telesalud en el componente de Teleconsulta brindando asistencia técnica especializada y a distancia al personal de los establecimientos de salud de las regiones del país. Permitirá ofrecer diagnóstico y tratamiento especializado en el lugar de atención del paciente, ahorrando tiempo e importantes recursos a la institución y los familiares.

Los pacientes que acuden al INO, provienen de dos fuentes: los referidos de las instituciones públicas de salud de alta complejidad (segundo y tercer nivel de atención) a nivel nacional y de acuerdo al Sistema 
de Referencias y Contrarreferencias, y otros que llegan directamente a consulta externa con afecciones principalmente de baja complejidad (primer nivel de atención).

Por su condición de especialidad, todas las consultas del INO, denominadas consultas externas, deberían enfocarse solamente en patologías visuales de alta complejidad (segundo y tercer nivel). Sin embargo, el instituto también admite atención de patologías de baja complejidad (primer nivel), constituidos por trastornos menores y medición de la vista (refracción), que deberían ser atendidos en los establecimientos del Ministerio de Salud (MINSA). Y esta atención no es marginal, sino significativa, ya que las dos terceras partes de la demanda atendida corresponden al primer nivel de atención, restando apenas una tercera parte para las atenciones de alta complejidad (Instituto Nacional de Oftalmologia-MINSA, 2014).

Sin embargo, el presupuesto destinado a financiar las atenciones del primer nivel oficialmente no existe en las cuentas presupuestales del instituto, pues todas las consultas externas se catalogan como atención médica especializada. Es decir, se estaría dando el desvío de recursos del presupuesto de alta complejidad para asignarlos a las atenciones de baja complejidad, con lo cual el INO no estaría haciendo uso eficiente de su presupuesto e incumpliendo con uno de sus objetivos pilares: maximizar el número de atenciones de patologías de alta complejidad.

De acuerdo a lo manifestado, en toda la consulta externa va a ser importante identificar y determinar el presupuesto ejecutado únicamente en atenciones de primer nivel de atención para conocer su impacto y cuantía en el presupuesto ejecutado de consulta externa, así como el nivel en que los mismos están afectando el presupuesto ejecutado en atenciones de alta complejidad. Esa es la inquietud del presente trabajo de investigación.

En este sentido, se plantea el problema del estudio en los términos siguientes: ¿Cuál es el impacto en el presupuesto de consulta externa del Instituto Nacional de Oftalmología (INO) de la atención en patologías de baja complejidad, que solo requieren ser atendidos en establecimientos de salud de primer nivel, durante el período 2010 - 2015? Responder a esta interrogante va a requerir conocer los montos 
de los presupuestos ejecutados en consulta externa y en atenciones de patologías de baja complejidad, para luego compararlos.

La solución del problema de investigación va a permitir al INO, conocer en qué medida está haciendo uso eficiente de su presupuesto. Va a permitir a sus autoridades, si fuera el caso, implemetar medidas destinadas a mejorar la eficiencia de la ejecución presupuestal, es decir, hacer un mejor uso de los recursos de la institución. Todo esto para cumplir con los objetivos de un establecimiento de alta especialidad.

\section{Metodología}

Se trata de un estudio descriptivo, no experimental - transversal. La variable de estudio es el Presupuesto ejecutado en consulta externa, la cual se divide en dos dimensiones Presupuesto ejecutado en patologías de alta complejidad (2do y 3er nivel) y Presupuesto ejecutado en patologías de baja complejidad (1er nivel). Este primer nivel se divide a su vez en dos indicadores Presupuesto ejecutado en consulta general y Presupuesto ejecutado en consulta de refracción.

El problema del estudio fue determinar el nivel porcentual (impacto) del presupuesto de las patologías de baja complejidad en el presupuesto de consulta externa. Requirió conocer los montos de los presupuestos implicados en el problema de estudio (consulta externa y consulta externa de 1er nivel), para luego compararlos y determinar el impacto, con información referida a un período determinado (2010 - 2015), y procedente del Instituto Nacional de Oftalmología (INO).

Las unidades de análisis correspondieron a las patologías de baja complejidad, que en total hicieron una población de 43 defectos visuales. En el estudio se consideraron como muestra todas las patologías de baja complejidad. Para la selección de estas patologías se recurrió a la Clasificación Internacional de las Enfermedades (CIE 10) y al Plan de Aseguramiento en Salud (PEAS), que permitieron identificar los diagnósticos oftalmológicos que corresponde al 1er nivel de atención (baja complejidad) y que son atendidos en los consultorios externos del Instituto, como consulta general y consulta por refracción (acomodación y medida de la vista). 
Cabe indicar que un determinado defecto o enfermedad visual siempre va a ser atendido en el primer nivel de atención, sea por diagnóstico que corresponde a este nivel o por seguimientos referidos de un nivel superior.

La información correspondió a la estadística de las atenciones prestadas por el Instituto, las cuales se han recolectado mediante la técnica del análisis documental. Para ello, se contó con la base de datos del total de las atenciones realizadas en los consultorios de las diferentes especialidades y sub especialidades del INO.

Por otro lado, en el Instituto y de manera genérica, los diagnósticos de estas patologías se realizan a través de dos procedimientos: Consulta médica especializada (código 99203) con trastornos del 1er, 2do y 3er nivel de atención, y Refracción y medición de la vista (código 92015) con trastornos de acomodación y refracción (primer nivel). Es en el primer procedimiento donde se incluyen todos los niveles de atención y en el cual fue necesario identificar y separar las patologías que corresponden al 1er nivel de atención.

Al respecto, de la información disponible en los documentos del INO, se diferenció visualmente aquellas consultas que correspondían exclusivamente al 1er nivel de atención, y dentro de éste, las consultas generales y de refracción. De esta manera, se cuantificó el número de atenciones en los dos tipos de consultas requeridas.

De la misma manera, con la información ya disponible en los documentos del INO sobre el presupuesto ejecutado en consulta externa y los costos unitarios de los procedimientos médicos, se procedió al cálculo del presupuesto ejecutado en consulta externa del 1er nivel y sus tipos, consulta general y consulta de refracción. Para tal efecto, los costos unitarios de los procedimientos se multiplicaron por el número de atenciones prestadas por el Instituto en cada tipo de consultas, es decir, los costos totales representaron a la postre, el presupuesto ejecutado. De esta manera, se llegó a conocer el monto de los presupuestos anuales y del período, en cada caso.

Finalmente, para conocer el impacto solicitado, se procedió a realizar la comparación del presupuesto ejecutado en el 1er nivel de atención con 
respecto al presupuesto ejecutado en consulta externa. De esta manera, el impacto es expresado en términos porcentuales.

$$
\text { Impacto }(\%)=\frac{\text { Presupuesto ejecutado en } 1 \text { er nivel de atención }}{\text { Presupuesto ejecutado en consulta externa }}
$$

\section{Marco Teórico}

A pesar de la aparente importancia que tienen las afecciones visuales para las sociedades y economías de los países, no ha sido posible encontrar, a nivel nacional e internacional, antecedentes que reflejen la misma situación planteada en el problema de estudio. Ello ha obligado a hacer uso de estudios previos que en cierta medida guardan consonancia con el manejo de los presupuestos públicos. En tal sentido, puede decirse que el presente estudio es el primero en su tipo.

En este sentido, el trabajo de Tanaka, tiene como objetivo analizar la aplicación del presupuesto por resultados (PpR) en la gestión presupuestal de ciertos programas estratégicos MINSA. Entre los principales hallazgos se tiene que, el presupuesto del MINSA no ha mostrado un incremento significativo en la asignación de recursos por parte del MEF, siendo esta asignación inercial, sin vinculación con lo ya obtenido. En el MINSA se detecta una escasa relación entre el planeamiento y el presupuesto por resultados; no disponen de instancias superiores de coordinación presupuestal, lo cual atenta para una mejor y mayor articulación económica entre los distintos instrumentos - planes y programas - comprometidos en el gasto público. Por otro lado, la normatividad sobre la ejecución presupuestal no beneficia a una aplicación por resultados; está direccionada a una política de control (cumplimento de normas, leyes y procedimientos) antes que a la generación de resultados tangibles y beneficiosos para la población (Tanaka, 2011)

Prieto, evalúa la posible influencia de la aplicación del presupuesto por resultados (PpR) en la calidad del gasto de algunas municipalidades del Perú. Encuentra que, la gestión del PpR contribuye a elevar la calidad del gasto, debido a que mejoran los estándares de vida de la comunidad. Este mejoramiento se explica porque los presupuestos son destinados 
a programas estratégicos que disminuyen los grados de severidad de los problemas más sentidos por la población, tales como desnutrición, educación y demás servicios. Sin embargo, a pesar de ello, encuentra que la toma de decisiones no resulta ser del todo eficiente, debido a que, la prioridad de los gestores está centrada en los gastos de capital y no en los gastos que benefician a la población. Por otro lado, los indicadores que evalúan la gestión presupuestal no están alineados con los criterios del PpR, ya que, por una parte, miden la magnitud del gasto público, pero no la calidad de este gasto (beneficios a la población), por otra, son desconocidos por los propios evaluadores de la gestión (Prieto, 2012).

Finalmente, Escobar y Hermoza, analizan la relación del presupuesto por resultados (PpR) con la calidad del gasto, en un establecimiento regional de salud. Encuentran que, entre las variables, PpR y calidad del gasto, existe una relación directa. Similar asociación, encuentran entre sus dimensiones correspondientes - estrategias y técnica presupuestal por parte del $\mathrm{PpR}$, y eficiente del gasto por calidad del gasto -, respectivamente (Escobar y Hermoza, 2015).

El presupuesto es el documento y herramienta legal de mayor importancia en la administración pública. Es el instrumento de gestión estatal del que hace uso todo gobierno para tomar decisiones, realizar actividades y lograr los resultados previstos, buscando en todo ello, eficiencia y eficacia en cada una de las gestiones realizadas por las instituciones públicas (Ortega y García, 2004). Estos resultados se expresan principalmente como dación de servicios a la población, el logro de metas sectoriales o de cobertura y el cumplimiento de los objetivos considerados en los planes de desarrollo nacional (Rodríguez, 2008).

En conclusión, el presupuesto es un medio fundamental que anticipa las estimaciones de ingresos y gastos para la realización de ciertas actividades a cargo de las entidades gubernamentales. Permite prever los gastos que se han de efectuar en un determinado período y asegurar los ingresos que tales gastos requieren.

Para el Ministerio de Economía y Finanzas (MEF, 2018), el presupuesto

Es un instrumento de gestión del Estado para el logro de resultados a favor de la población, a través de la prestación de servicios y 
logro de metas de cobertura con equidad, eficacia y eficiencia por las Entidades Públicas. Establece los límites de gastos durante el año fiscal, por cada una de las Entidades del Sector Público y los ingresos que los financian, acorde con la disponibilidad de los Fondos Públicos, a fin de mantener el equilibrio fiscal.

En la gestión de los sistemas presupuestarios se han utilizado diferentes tipos de presupuestos, de los cuales resaltan nítidamente dos: presupuesto por programas y presupuesto por resultados (PpR). El presupuesto por programas ha sido y quizás todavía es, el modelo más utilizado en los países, incluyendo el Perú. Es el presupuesto tradicional de los países. Se trata de la evaluación de distintas alternativas o programas de ejecución presupuestal y posterior elección de una de ellas en el afán de lograr los objetivos previstos.

A inicios de la década de 1,970 y como reacción a los problemas fiscales se creyó conveniente utilizar y adaptar una serie de mecanismos y herramientas que venía utilizando el sector privado para incrementar su eficiencia, y cuya característica principal era la evaluación y financiamiento de los productos y resultados, el cual se denominó Presupuesto por Resultados (PpR). Es un modelo de gestión estatal que relaciona la aplicación de recursos con los productos y resultados obtenidos y medibles en función de los usuarios (Ministerio de Economía y Finanzas, 2018). Según Marcel (2006, Taller sobre gestión intensiva de proyectos, citado por: Córdova, F. (2007) en: El Presupuesto Por Resultados: Un Instrumento Innovativo de Gestión Pública Chile, p 11.), el PpR es un proceso de reformas que "involucra la reestructuración de los procesos presupuestarios, para incorporar información sobre desempeño, destino de los recursos, mandatos y compromisos, evaluación de resultados mediante indicadores y sostenibilidad de las inversiones".

El PpR busca incrementar la eficiencia presupuestal. Ello obliga a un cambio de énfasis de la atención pública, pasando del control del gasto a la obtención de resultados en el lado de la población. Es decir, la oferta pública tiene que acomodarse a la demanda ciudadana. Para tal efecto, el modelo diseña, valida y aplica nuevos procedimientos y técnicas metodológicas al ciclo de la gestión presupuestal. 
Los resultados parecen acompañar al PpR, puesto que se ha dado y se sigue dando una utilización progresiva del modelo en todas las instancias y niveles de gobierno. Pero, el cambio de la atención pública ha obligado también a un cambio en el marco institucional. Por esta razón, se han dado cambios profundos en la normatividad que regula la gestión presupuestal del Estado.

La eficiencia que tanto busca el PpR se refiere a la utilización óptima de los productos por pate de la población. Es una eficiencia social. Pero los productos o servicios también tienen su propia eficiencia y está ubicada en los recursos que se utilizan para su fabricación. Se trata de una eficiencia productiva, es decir, el uso económico de los recursos. En tal sentido, una organización es más eficiente cuánto mayor es el nivel de productividad o economía con que usa sus recursos (Amaru, 2009). Ahora, dado que los recursos siempre son escasos, se debe hacer un uso óptimo de ellos (Bernal, 2007), lo cual se materializa a través de la productividad, rendimiento, capacidad instalada, etc.

En función del costo de los recursos, para Gimeno y Guirola (2003), la eficiencia supone que se es capaz de obtener el máximo de objetivos con el mínimo coste, o, el máximo de objetivos a partir de un coste dado, o bien, un objetivo prefijado con el mínimo coste posible. Es decir, el uso de los recursos implica un costo; entonces, para minimizar o mantener este costo se debe hacer un buen uso de ellos. Por buen uso se entiende el orden y la corrección de los métodos y procedimientos administrativos diseñados para obtener resultados previstos (Hernández y Rodríguez, 2008).

La eficacia, en cambio, se refiere al logro de los objetivos. Indica cuánto una institución logra sus objetivos programados. En tal sentido, una organización será más eficaz cuanto mayor sea el nivel de realización de sus metas (Amaru, 2009). Es la capacidad de hacer realidad los sueños, deseos u objetivos organizacionales, sin tener en cuenta los medios o procedimientos utilizados (Hernández y Rodríguez, 2008).

En la eficacia, la medición de los resultados obtenidos toma en cuenta varios aspectos previamente programados, tales como cantidad, calidad y oportunidad de lo producido, sean bienes o servicios. Depende de las actividades de trabajo, es decir, actividades pertinentes que llevan a las organizaciones a lograr resultados. En este sentido, la eficacia identifica 
un programa, procedimiento o técnica adecuada, que permite lograr con éxito los objetivos y metas formuladas.

\section{Resultados y Discusión}

Las Consultas Externas realizadas en los consultorios de las diferentes especialidades y sub especialidades en el periodo 2010-2015, totalizaron 1'588,527 atenciones. De este total, las atenciones con diagnóstico de primer nivel (general y refracción) ascendieron a 570,441; mostrando un comportamiento notoriamente decreciente durante el período de estudio. Estas consultas han representado el 36\% del total de consultas externas de 1er nivel, representando también el porcentaje de consultas que se han dejado de atender en los niveles 2 do y 3ro, es decir, en patologías de alta complejidad. (Tabla 1)

Tabla 1

Total de Consultas Externas y Patologías de Primer Nivel de Atención. INO, 2010-2015

\begin{tabular}{|lccccccc|}
\hline CONCEPTO & $\mathbf{2 0 1 0}$ & $\mathbf{2 0 1 1}$ & $\mathbf{2 0 1 2}$ & $\mathbf{2 0 1 3}$ & $\mathbf{2 0 1 4}$ & 2015 & TOTAL \\
\hline Consultas Externas & 234.653 & 233.610 & 289.210 & 298.772 & 294.743 & 237.539 & 1.588 .527 \\
$\begin{array}{l}\text { Consultas Externas con } \\
\text { Diagnósticos de Primer } \\
\text { Nivel }\end{array}$ & 113.364 & 109.538 & 112.130 & 91.061 & 84.789 & 59.559 & 570.441 \\
\hline $\begin{array}{l}\text { \% de Consultas externas } \\
\text { con Diagnósticos de }\end{array}$ & $48,31 \%$ & $46,89 \%$ & $38,77 \%$ & $30,48 \%$ & $28,77 \%$ & $25,07 \%$ & $35,91 \%$ \\
\hline \begin{tabular}{l} 
Primer Nivel \\
\hline
\end{tabular}
\end{tabular}

Fuente: Reporte Consultas INO 2010-2015

Elaboración: Propia.

Asimismo, del total de consultas de 1er nivel, 323,373 (57\%) correspondieron a consulta general y 247,068 (43\%) a consulta de refracción, mostrando ambos, un comportamiento notablemente decreciente, durante el período de estudio, en consonancia con el comportamiento de las consultas de 1er nivel. (Tabla 2)

De otra manera, los costos unitarios de los procedimientos médicos en consulta general y consulta de refracción manifestaron un incremento del $28 \%$ y $18 \%$, respectivamente durante el período de estudio, explicado principalmente por el incremento de los servicios públicos en un nivel del $116 \%$ en ambos procedimientos. (Tablas 3 y 4 ) 
Tabla 2: Consultas Externas con diagnóstico de Primer Nivel de Atención por tipo de consulta.

INO, $2010-2015$

\begin{tabular}{|lccccccc|}
\hline CONCEPTO & $\mathbf{2 0 1 0}$ & $\mathbf{2 0 1 1}$ & $\mathbf{2 0 1 2}$ & $\mathbf{2 0 1 3}$ & $\mathbf{2 0 1 4}$ & $\mathbf{2 0 1 5}$ & $\begin{array}{c}\text { TOTAL } \\
\mathbf{2 0 1 0 - 2 0 1 5}\end{array}$ \\
\hline $\begin{array}{l}\text { Consultas Externa en Consulta } \\
\text { General }\end{array}$ & 69.248 & 65.380 & 62.255 & 53.371 & 41.562 & 31.557 & 323.373 \\
$\begin{array}{l}\text { Consultas Externa en Consulta de } \\
\text { Refracción }\end{array}$ & 44.116 & 44.158 & 49.875 & 37.690 & 43.227 & 28.002 & 247.068 \\
\hline $\begin{array}{l}\text { Consultas externas con Diagnóstico } \\
\text { de Primer Nivel }\end{array}$ & 113.364 & 109.538 & 112.130 & 91.061 & 84.789 & 59.559 & 570.441 \\
\hline
\end{tabular}

Fuente: Reporte Consultas INO 2010-2015

Elaboración: Propia

Tabla 3

Costos Asistenciales en Consulta general. INO, 2010 - 2015

Nombre del Procedimiento: Consulta médica especializada

Código del Procedimiento: 99203

Nombre Común: Consulta Oftalmológica Especializada

\begin{tabular}{|c|c|c|c|c|c|c|c|c|}
\hline Años & 2010 & 2011 & 2012 & 2013 & 2014 & 2015 & $\begin{array}{l}\text { Diferencia en } \\
\text { Soles } \\
2010-2015\end{array}$ & $\begin{array}{l}\text { Variación \% } \\
\text { 2010-2015 }\end{array}$ \\
\hline \multicolumn{9}{|c|}{ COSTOS FIJOS } \\
\hline Recurso Humano & 10,27 & 10,34 & 10,45 & 11,06 & 13,05 & 14,24 & 3,97 & $39 \%$ \\
\hline Costo Depreciación & 2,50 & 2,50 & 2,50 & 2,60 & 2,60 & 2,60 & 0,10 & $4 \%$ \\
\hline Costo Fijo & 12,78 & 12,84 & 12,95 & 13,66 & 15,65 & 16,84 & & \\
\hline \multicolumn{9}{|c|}{ COSTOS VARIABLES } \\
\hline $\begin{array}{l}\text { Insumos de Servicios y Material } \\
\text { Médico }\end{array}$ & 3,22 & 3,22 & 3,16 & 3,11 & 3,11 & 3,08 & $-0,14$ & $-4 \%$ \\
\hline $\begin{array}{l}\text { Costo Total Medicamento y } \\
\text { Material Médico }\end{array}$ & 0,173 & 0,173 & 0,169 & 0,175 & 0,175 & 0,168 & $-0,004$ & $-2 \%$ \\
\hline Total Servicios Públicos: & 0,65 & 0,78 & 0,67 & 0,80 & 0,86 & 1,41 & 0,76 & $116 \%$ \\
\hline Total Costo Variable & 4,05 & 4,17 & 4,00 & 4,09 & 4,15 & 4,66 & 0,61 & $15 \%$ \\
\hline Total Costo Directo & 16,83 & 17,01 & 16,95 & 17,76 & 19,80 & 21,50 & 4,67 & $28 \%$ \\
\hline Total Costo Indirecto & 4,59 & 4,64 & 4,62 & 4,84 & 5,40 & 5,86 & 1,27 & $28 \%$ \\
\hline Costo total & 21,41 & 21,65 & 21,58 & 22,60 & 25,20 & 27,36 & 5,95 & $28 \%$ \\
\hline
\end{tabular}

Fuente: Costos estándar INO 2010-201

Elaboración: Propia 
Tabla 4

Costos Asistenciales en Consulta de Refracción. INO, 2010 - 2015

Nombre del Procedimiento: Refracción y medición de la visión

Código del Procedimiento: 92015

Nombre Común: Refracción o medida de vista

\begin{tabular}{|c|c|c|c|c|c|c|c|c|}
\hline AÑOS & 2010 & 2011 & 2012 & 2013 & 2014 & 2015 & $\begin{array}{c}\text { Diferencia en } \\
\text { Soles 2015-2010 }\end{array}$ & $\begin{array}{c}\text { Variación \% } \\
2015-2010\end{array}$ \\
\hline \multicolumn{9}{|c|}{ COSTOS FIJOS } \\
\hline Total Recurso Humano & 6,14 & 6,19 & 6,40 & 6,76 & 7,25 & 7,40 & 1,26 & 0.21 \\
\hline Total Depreciación & 1,61 & 1,61 & 1,61 & 1,62 & 1,81 & 1,81 & 0,19 & $12 \%$ \\
\hline Costo Total Fijo & 7,76 & 7,80 & 8,01 & 8,37 & 9,06 & 9,21 & 1,45 & $19 \%$ \\
\hline \multicolumn{9}{|c|}{ COSTOS VARIABLES } \\
\hline $\begin{array}{l}\text { Insumos de Servicios y } \\
\text { Material Médico }\end{array}$ & 3,24 & 3,24 & 3,18 & 3,14 & 3,14 & 3,11 & $-0,13$ & $-4 \%$ \\
\hline $\begin{array}{l}\text { Total Insumos yMaterial } \\
\text { Médico }\end{array}$ & 0,173 & 0,173 & 0,169 & 0,175 & 0,175 & 0,168 & $-0,004$ & $-2 \%$ \\
\hline Servicios Públicos: & 0,65 & 0,78 & 0,67 & 0,80 & 0,86 & 1,41 & 0,76 & $116 \%$ \\
\hline Total Costo Variable & 4,07 & 4,19 & 4,02 & 4,12 & 4,18 & 4,69 & 0,62 & $15 \%$ \\
\hline Total Costo Directo & 11,83 & 11,99 & 12,03 & 12,50 & 13,24 & 13,90 & 2,07 & $18 \%$ \\
\hline Total Costo Indirecto & 3,31 & 3,36 & 3,37 & 3,50 & 3,71 & 3,89 & 0,58 & $18 \%$ \\
\hline Costo Total & 15,14 & 15,5 & 15,40 & 16,00 & 16,95 & 17,79 & 2,65 & $18 \%$ \\
\hline
\end{tabular}

Fuente: Costos estándar INO 2010-201

Elaboración: Propia

Por otro lado, la ejecución del presupuesto anual en consulta externa durante el período de estudio asciende a 48'031,861 soles, el cual representa el 21\% del presupuesto institucional ejecutado en el INO. Si bien las cifras absolutas indican un ligero incremento en el presupuesto externo, su comportamiento respecto al presupuesto institucional manifiesta una significativa disminución del 9\% durante el período. (Tabla 5)

Tabla 5

Porcentaje de Presupuesto Ejecutado en consulta externa, respecto al Presupuesto total ejecutado. INO, 2010 - 2015

\begin{tabular}{|lccccccc|}
\hline DETALLE & $\mathbf{2 0 1 0}$ & $\mathbf{2 0 1 1}$ & $\mathbf{2 , 0 1 2}$ & $\mathbf{2 0 1 3}$ & $\mathbf{2 0 1 4}$ & $\mathbf{2 0 1 5}$ & $\begin{array}{c}\text { TOTAL } \\
\text { PERIODO }\end{array}$ \\
\hline $\begin{array}{l}\text { Presupuesto Total } \\
\text { Ejecutado }\end{array}$ & 26.779 .116 & 33.046 .997 & 44.063 .303 & 41.942 .829 & 40.599 .385 & 46.801 .645 & 233.233 .275 \\
$\begin{array}{l}\text { Presupuesto en } \\
\text { Consulta externa }\end{array}$ & 7.398 .104 & 9.368 .770 & 7.300 .013 & 7.821 .050 & 7.085 .194 & 9.058 .730 & 48.031 .861 \\
\hline $\begin{array}{l}\text { \%Presupuesto en } \\
\text { Consulta externa }\end{array}$ & $28 \%$ & $28 \%$ & $17 \%$ & $19 \%$ & $17 \%$ & $19 \%$ & $21 \%$ \\
\hline
\end{tabular}

Fuente: SIAF Amigable

Elaboración: Propia 
De la misma manera, el presupuesto ejecutado en el 1er nivel de atención asciende a 11'306,027 soles, de los cuales 7'358,436 (65\%) corresponde a consulta general y 3’947,590 (35\%) a consulta de refracción. Todos muestran un comportamiento decreciente. (Tabla 6)

Tabla 6

Presupuesto ejecutado en Patologías de Primer Nivel por tipo de consulta. INO. 2010-2015

\begin{tabular}{|lccccccc|}
\hline PROCEDIMIENTO & $\mathbf{2 0 1 0}$ & $\mathbf{2 0 1 1}$ & $\mathbf{2 0 1 2}$ & $\mathbf{2 0 1 3}$ & $\mathbf{2 0 1 4}$ & $\mathbf{2 0 1 5}$ & COSTO TOTAL \\
\hline $\begin{array}{l}\text { Presupuesto en Consulta } \\
\text { General }\end{array}$ & 1.482 .720 & 1.415 .685 & 1.343 .212 & 1.205 .946 & 1.047 .443 & 863.431 & 7.358 .436 \\
$\begin{array}{l}\text { Presupuesto en Consulta } \\
\text { de Refracción }\end{array}$ & 667.747 & 677.918 & 768.075 & 602.905 & 732.763 & 498.183 & 3.947 .590 \\
\hline $\begin{array}{l}\text { Presupuesto ejecutado en } \\
\text { Primer nivel }\end{array}$ & 2.150 .466 & 2.093 .602 & 2.111 .288 & 1.808 .851 & $\mathbf{1 . 7 8 0 . 2 0 6}$ & $\mathbf{1 . 3 6 1 . 6 1 3}$ & $\mathbf{1 1 . 3 0 6 . 0 2 7}$ \\
\hline
\end{tabular}

Fuente: Estimación de Costos 2010-2015

Elaboración: Propia

Comparando montos, el presupuesto ejecutado en el 1er nivel de atención representa el $23.54 \%$ del total del presupuesto ejecutado en consulta externa del INO, durante el período de estudio. Este nivel representa también el impacto de las atenciones de baja complejidad en el presupuesto de consulta externa del INO. Por último, representa también, el porcentaje de reducción del presupuesto para las atenciones de las patologías de alta complejidad. Muestran un comportamiento notoriamente decreciente, durante el periodo de estudio. (Tabla 7)

Tabla 7

Porcentaje de Presupuesto Ejecutado en Primer Nivel, respecto al Presupuesto Ejecutado en consulta externa. INO 2010-2015

\begin{tabular}{|lccccccc|}
\hline DETALLE & $\mathbf{2 0 1 0}$ & $\mathbf{2 0 1 1}$ & $\mathbf{2 , 0 1 2}$ & $\mathbf{2 0 1 3}$ & $\mathbf{2 0 1 4}$ & $\mathbf{2 0 1 5}$ & $\begin{array}{c}\text { TOTAL } \\
\text { PERIODO }\end{array}$ \\
\hline $\begin{array}{l}\text { Presupuesto Consulta } \\
\text { externa }\end{array}$ & 7.398 .104 & 9.368 .770 & 7.300 .013 & 7.821 .050 & 7.085 .194 & 9.058 .730 & 48.031 .861 \\
$\begin{array}{l}\text { Presupuesto Ejecutado } \\
\text { en Primer Nivel }\end{array}$ & 2.150 .466 & 2.093 .602 & 2.111 .288 & 1.808 .851 & 1.780 .206 & 1.361 .613 & 11.306 .027 \\
\hline $\begin{array}{l}\text { \% Presupuesto Eje- } \\
\text { cutado en primer nivel }\end{array}$ & $\mathbf{2 9 , 0 7 \%}$ & $\mathbf{2 2 , 3 5 \%}$ & $\mathbf{2 8 , 9 2 \%}$ & $\mathbf{2 3 , 1 3 \%}$ & $\mathbf{2 5 , 1 3 \%}$ & $\mathbf{1 5 , 0 3 \%}$ & $\mathbf{2 3 , 5 4 \%}$ \\
\hline
\end{tabular}

Fuente: SIAF Amigable, Estimación de costos

Elaboración Propia 
El Instituto brinda atención especializada y altamente especializada, con la finalidad de disminuir las tasas de prevalencia de las enfermedades que causan discapacidad por ceguera evitable. El presente estudio concluye que, con respecto al presupuesto asignado a financiar los costos de las Atenciones Especializadas, el Instituto no ejecuta eficientemente el presupuesto institucional dirigiendo un porcentaje significativo de más del $23 \%$, en atender patologías que deben ser atendidas y tratadas en el primer nivel de atención, es decir, en los puestos y centros de salud y hospitales de baja complejidad, que corresponden al MINSA.

Del total de consultas en el 1er nivel de atención, el 43\% corresponde a consultas de refracción. Este nivel representa un alto porcentaje en la atención de patologías visuales sumamente sencillas (medición de la vista) y comprometen el 35\% del presupuesto del nivel de atención. Con ello, se manifiesta aún más la falta de eficiencia en el uso de los recursos presupuestarios, que solamente deberían direccionarse a las atenciones de alta complejidad.

Sin embargo, esta deficiencia en el uso del presupuesto de alta especialidad durante el período, tiene una marcada tendencia a ser corregida en el tiempo. Mientras la atención en consulta externa tiende a ser progresiva, la atención en consultas de 1er nivel tiende a ser regresiva. Según la estimación por regresión lineal (pendiente: -10,409 consultas), la brecha de 59,559 atenciones del 1er nivel del último año del período de estudio, se cerraría en el año 2 022. En este año, todas las consultas externas pasarían a ser de alta especialidad.

Por otro lado, si bien el presupuesto ejecutado en consulta externa (tabla 5) representó el 21\% del presupuesto total ejecutado, durante el periodo; se observa una marcada disminución de la ejecución presupuestaria, pasando del 28\% al inicio del periodo a un 19\% al final del mismo. Ello significa que el presupuesto ejecutado en consulta externa, ha disminuido notoriamente en detrimento de las atenciones visuales, que más bien debería mantenerse e inclusive aumentar. Es decir, no solamente se da la falta de eficiencia en el uso de los presupuestos, también la disminución del mismo, en términos relativos.

De otra parte, la asignación del presupuesto a niveles de atención que no son de su competencia estaría sugiriendo que en el INO no existe con- 
trol y evaluación, ni menos coordinación sistemática con las entidades superiores del MINSA, como suele ocurrir hasta ahora en otras entidades del Estado (Tanaka, 2 011). La aplicación de un tipo de presupuesto también es importante, si bien en el Estado se está promoviendo la aplicación del PpR, se percibe que el INO hasta el momento no ha implementado totalmente su aplicación; de hacerlo, mejoraría la calidad y eficiencia del gasto público (Prieto, 2012; Escobar y Hermoza, 2 015).

En síntesis, las conclusiones finales del trabajo son:

1. El impacto en el presupuesto institucional en consulta externa del INO de las atenciones en patologías de baja complejidad durante el período 2010 - 2015 es del 23,54\%. Este nivel representa también el porcentaje en que el presupuesto de alta complejidad ha sido afectado. Esta afectación en términos de demanda ha significado dejar de atender 570,441 consultas de alta especialidad, lo que representa el $36 \%$ de las consultas externas.

2. El presupuesto ejecutado en consulta externa (baja y alta complejidad) asciende a 48'031,861 soles, que representa el $21 \%$ del total del presupuesto institucional ejecutado, durante el período.

3. El presupuesto ejecutado en las patologías de primer nivel durante el período asciende a S/,11'306,026,55. De estos, el 65\% corresponden a consulta general y el $35 \%$ a consulta de refracción.

\section{Reflexiones Finales}

El Instituto debe reducir los costos de las atenciones de baja complejidad y con ello su presupuesto, mientras que progresivamente se va cerrando la brecha de estas atenciones para abocarse exclusivamente en las patologías de alta complejidad. Esto permitiría el uso eficiente de los recursos presupuestarios, orientados al cumplimiento de los objetivos institucionales del INO. Para garantizar la reducción de los costos y el cierre de la brecha en los próximos cinco años, se debe fortalecer e implementar ciertas medidas de gestión, tales como: Acuerdos de gestión interinstitucional, mejora de los procesos de Referencia y Contrarreferencia, y el desarrollo de la Telesalud. 
En los acuerdos de gestión interinstitucional, las prestaciones de salud se deben brindar según el nivel de complejidad de la oferta. Por tanto, se recomienda que el INO realice acuerdos u otros modelos de gestión con establecimientos de salud del primer nivel de atención, que permitan la rotación de su personal médico hacia estos establecimientos y brindar atención especializada a sus pacientes. Esto redundaría en una reducción de los costos variables en las atenciones de baja complejidad de la consulta externa del INO, permitiendo orientar ese presupuesto a la atención de patologías de alta complejidad.

En los procesos de referencia y contrarreferencia, el fortalecimiento debe darse a través de una mejora de los mismos. El uso adecuado de las referencias permitirá brindar atención especializada a pacientes que provienen de establecimientos de salud de menor complejidad y que requieren hacer extensivo su tratamiento en establecimientos de mayor capacidad resolutiva, como el INO. Concluido el mismo, y a través de la contrarreferencia, el paciente puede continuar con su atención en los establecimientos de origen de la referencia, sin verse en la necesidad de regresar al Instituto. Todo ello, permitirá descongestionar la consulta externa del INO, generando el acceso a pacientes que requieran atención especializada y por lo tanto, haciendo un uso más eficiente de los recursos presupuestarios.

El gran avance de las Tecnologías de la Información y de la Comunicación -TIC en el campo de la salud, permiten brindar servicios de salud profesional a distancia (Telesalud), facilitando el acceso a la atención médica especializada de los usuarios a nivel nacional, principalmente de zonas rurales y de los establecimientos con limitada capacidad resolutiva. Todo esto mediante dos modalidades. Con la Teleconsulta (atención de pacientes a distancia) el Instituto atiende la referencia de pacientes con patologías de alta complejidad; de la misma manera, con la Telecapacitación (capacitación de profesionales de la salud a distancia), se podrá atender a pacientes con patologías de baja complejidad a través de los profesionales, previamente capacitados por el Instituto.

La política de reducción de las atenciones de primer nivel, ha tenido dos claras implicancias: en la organización de los servicios de salud del INO y en la conducta de los pacientes. Por una parte, se ha recuperado el 
inicio a la continuidad entre los "niveles de atención" en el contexto de las "redes integradas de servicio", expresado en el uso obligatorio de las referencias y contrarreferencias por parte de la institución y los pacientes. Ello está evitando la duplicación de diagnósticos por parte de establecimientos de diferentes niveles de capacidad resolutiva. De esta manera, el INO está sincerando su nivel de atención.

Por otra parte, como se comprenderá, la reducción de las atenciones de primer nivel no fue bien recibida por los pacientes, pues reducía significativamente sus oportunidades de atención en este centro especializado. Sin embargo, esto fue generando una paulatina comprensión y educación de los pacientes en el sentido de acudir siempre con su referencia de un establecimiento del MINSA. De esta manera, el paciente se fue formalizando, y ese comportamiento se mantiene en camino.

\section{Referencias Bibliográficas}

Amaru, Antonio (2009). Fundamentos de Administración. México: Pearson Educación, 488 p.

Bernal, Cesar (2007). Introducción a la Administración de las Organizaciones. México: Person Prentice Hall, 336 p.

Escobar, Deisy y Hermoza, Gaby (2015). El Presupuesto por Resultados en la Calidad del Gasto Público de La Unidad Ejecutora de la Dirección Regional de Salud Huancavelica, Año 2014. Tesis para obtar el Titulo Profesional de Licenciado en Administracion, Facultad de Ciencias Empresariales Universidad Nacional de Huancavelica, Huancavelica. Perú, 171 p.

Gimeno, Juan y Guirola, José (2003). Principios de Economía. España, Mcgraw Hill, 336p.

Hernández y Rodríguez, Sergio (2008). Administración Teoría, proceso áreas funcionales y estrategias para la competitividad. México: Mc Graw Hill, 442 p.

Instituto Nacional de Oftalmologia-INO (2014). Análisis de la Situacion de Salud 2014. Lima: INO, 472 p.

Marcel, Mario (2006). Taller sobre gestión intensiva de proyectos, Gestión Burocrática y Gestión Presupuestaria por Resultados: Experiencia Internacional, Río de Janeiro Citado por: Córdova, F, (2007) en: El Presupuesto Por Resultados: Un Instrumento Innovativo de Gestión Pública Chile, p 11, 18 p. 
Ministerio de Economía y Finanzas-MEF (2018). Presupuesto por Resultados. Obtenido de https://www.mef.gob.pe/es/presupuesto-por-resultados/ ique-es-ppr

Ministerio de Economía y Finanzas-MEF (2018). Presupuesto Público. Obtenido de https://www.mef.gob.pe/es/presupuesto-publico-sp-18162

Mostajo, Rossana (2002). Serie de Gestión Pública. El Sistema Presupuestario en el Perú, Instituto Latinoamericano y del Caribe de Planificación Económica y Social - ILPES. Santiago de Chile, Naciones Unidas - CEPAL, 90 p.

Ortega, Alfonso y García, Héctor (2004). Hacienda Pública, Bogotá: Ediciona Ecoe, $2017 \mathrm{p}$.

Prieto, Marlon (2012). Influencia de la Gestión del Presupuesto por Resultados en la Calidad del Gasto en las Municipalidades del Perú (2006 - 2010). Caso: Lima, Junín y Ancash. Para optar el Grado Académico de Doctor en Contabilidad y Finanzas, Facultad de Ciencias Contables, Económicas y Financieras. USMP Lima, Perú: 141 p.

Rodríguez, Pedro (2008). Presupuesto Público, Programa Administración Pública Territorial, Escuela Superior de Administración Pública. Bogotá, 119 p.

Tanaka, Cecilia (2011). Influencia del Presupuesto por Resultados en la Gestión Financiera Presupuestal del Ministerio de Salud. Tesis para optar el Grado de Magister, Facultad de Ciencias Económicas de la UNMSM. Lima, Perú, 139 p.

Tirado, Oslay; Hernández, Ariana; Rivas, María del Carmen y Linares, Marilyn (2011). La ceguera desde la perspectiva de los estudios de Ciencia-Tecnología-Sociedad, Rev Hum Med, Dic 2011, vol, 11, No, 3, p, 413-432.

UNESCO y Universitat Politécnica de Catalunya (2009). Cátedra UNESCO Salud Visual y Desarrollo, Informe de la Salud Visual en Sudamérica 2008, 238 p.

\section{Notas al final}

1 Durante mi permanencia laboral en el ex Instituto de Gestión de Salud (IGSS), al revisar la ejecución presupuestal de las instituciones de salud, nació la inquietud por establecer la eficiencia en el uso del presupuesto institucional por parte del Instituto Nacional de Oftalmología (INO) dado que la institución da cobertura a patologías de baja complejidad, siendo una institución de alta capacidad resolutiva. El artículo es de tipo Revisión de Tesis presentado por el autor para optar el grado académico de Magister en Economía.

2 Economista, Universidad Nacional Mayor de San Marcos, Lima, Perú. Ex director ejecutivo de la Oficina de Planeamiento Estratégico del Instituto Nacional de Rehabilitación (INR), Avda. El Morro s/n, Chorrillos. Estudios de Magister en economía con mención en Desarrollo Empresarial y Regional en la Universidad Nacional Mayor de San Marcos, Lima, Perú. Calle Germán Amezaga 375, Lima, Perú. Correo-e: marcuadro@yahoo.com. 
